\title{
Planet Beehive
}

\author{
Freya Mathews ${ }^{1}$
}

Honeybees have long excited the interest of philosophers and natural historians. In ancient times tracts on them were written by Aristotle, Aristomachus, Cato, Varro, Pliny, Palladius and Virgil, and in the early modern period scientific studies began with Jan Swammerdam, who combined scientific method with piety in his Bible of Nature (1737), Réaumur who devoted a volume to honeybees in his Notes to Serve for a History of Insects and François Huber, who did not allow his own physiological blindness to hamper his New Observations of Bees (1789) (Maeterlinck). For ardour, however, no one could surpass Maurice Maeterlinck, whose Life of the Bee (1901), probably the most famous of all treatises on the honeybee, suffuses the idea of the bee with nostalgia for Edenic vistas of fruitand flower-laden domestic abundance and tranquillity.

Let us pause with Maeterlinck for a moment and savour the way, for him, the image of the beehive conjures orderliness, virtue, peacefulness and a pervasive honeyed sweetness that perhaps reflects his sense of the world of his boyhood. 'I have not yet forgotten the first apiary I saw', he writes,

where I learned to love the bees. It was many years ago, in a large village of Dutch Flanders, the sweet and pleasant country ... that gladly spreads out before us, as so many pretty, thoughtful toys, her illuminated gables, and wagons and towers; her cupboards and clocks that gleam at the end of the passage; her little trees, marshalled in line along quays and canalbanks, waiting, one might almost think, for some quiet, beneficent ceremony; her boats and her barges ... her flowerlike doors and windows, immaculate dams, and elaborate, many-coloured drawbridges; and her little varnished houses, bright as new pottery, from which bell-shaped dames come forth, all a-glitter with silver and gold, to milk the cows in the white-hedged fields, or spread the linen on flowery lawns...' (Maeterlinck, Chapter 1)

This well-scrubbed world of houseproud feminine industry is inextricably associated, in Maeterlinck's mind, with the idea of the beehive, for it was in this 'sweet and pleasant country' that, as a young boy, he had come to know an old recluse and sage, whose 'happiness, like the Scythian philosopher's, lay all in the beauties of his garden; and best-loved and visited most often, was the apiary,

1 A different version of this paper appeared under the title 'Planetary Collapse Disorder: The Honeybee as Portent of the Limits of Ethics' in Environmental Ethics 32.4 (2010). 
composed of twelve domes of straw, some of which he had painted a bright pink, and some a clear yellow, but most of all a tender blue; having noticed ... the bees' fondness for this colour' (Maeterlinck, Chapter 1). Maeterlinck goes on to speak of the hives lending new meaning to the flowers and the silence, the balm of the air and the rays of the sun, drawing us closer, by their presence, to the 'festival spirit of nature'.

It can hardly be said, in light of this testimony, that honeybees have been unloved. And I think that the aura of ancient fable and legend that still hovers around the honeybee remains attractive to us all. But I also think it would be fair to say that today, outside of entomological and amateur beekeeping circles, honeybees by and large have little place in our cultural imagination. It has not entirely slipped our minds that the honey on our table is produced by bees, but bees' role in the processes of pollination, and indeed the processes of pollination themselves, are generally only vaguely understood and entirely taken for granted.

Of course most animal species, apart from those that are either most conspicuous and charismatic or most obviously indentured to us, have also generally been taken for granted, at least by Western societies. We stop taking them for granted as, one by one, they suddenly show up on our lists of the rare or endangered or even the vanished. We have seen this happen with countless species of mammal, bird, amphibian and fish. Even if few people are yet aware of the staggering rates of endangerment on the planet today- $23 \%$ of mammals, $23 \%$ of birds, $12 \%$ of reptiles and $32.5 \%$ of amphibians ${ }^{2}$ - people in modern societies are certainly aware of endangerment as an issue. However, when they think endangerment they think polar bear, blue whale, tiger, orang-utan, sea turtle, river dolphin, albatross, maybe Wollemi pine or some of the pitcher plants. But until very recently, as of a couple of years ago, they were not likely to think insect, except perhaps for a few ornate species of butterfly. Insects have remained out-offocus, backdrop to the life world, a little-known and insignificant empire that we have often assumed might be "all that was left" after planetary holocausts caused by us.

But now it is the insects' turn to come into focus. Even insects, it transpires, are under threat. This has come to our attention mainly via the plight of the honeybee, which we have noticed because honeybees are, after all, vital to our interests, even if most of us have forgotten this. How many other insect species have disappeared, or are in the process of disappearing, without our noticing? Who can say? We can't know if a species has disappeared if we didn't know it was there in the first place, and of an estimated total of 10 million insect species on Earth we had, by 2006, identified only 900,000 (Wilson 32). Insects are a relative blind spot in our moral and cultural, and even our ecological,

2 These are the figures according to the International Union for the Conservation of Nature (Wilson 80). 
imagination. But in the last two years a third of all honeybees have mysteriously disappeared in the United States, 800,000 colonies in 2007, one million in $2008 .^{3}$ Large numbers have also collapsed in Canada, Europe, Asia and South America.

Being unused to thinking about insects, it is hard to know how to approach the issue of honeybee decline and possible extinction in cultural terms. Is the case of the disappearing honeybees an ethical issue? Should we be asking about the moral considerability of individual bees, of bee colonies, of bees as species? Perhaps, but affirming the moral value of individual bees or bee colonies or bees as a species doesn't quite seem to get to grips with the peculiar horror we feel at the current unexplained - but clearly anthropogenic - disappearance of honeybees. It's not the same kind of horror - the moral outrage - we feel when we hear of atrocities and genocides inflicted on people. Nor is it even quite the same moral anguish we feel when we hear of vast losses of dolphins and seals, penguins and albatrosses incurred as 'by-catch' in the fishing industry, for instance, or the destruction and endangerment of orang-utans as South East Asian forests are converted to crops for bio-fuels. What we feel, in the case of marine animals and orang-utans, is indeed moral outrage as we witness creatures with as much right to live and blossom as ourselves being crushed in the relentless human drive to turn every last quantum of biological resource on this planet to our own use. Confronting the mass disappearance of honeybees, however, in parts of Europe, South America, Asia and particularly the USA, incurs a slightly different register of despair. It is this different register of despair that I would like to explore in this chapter.

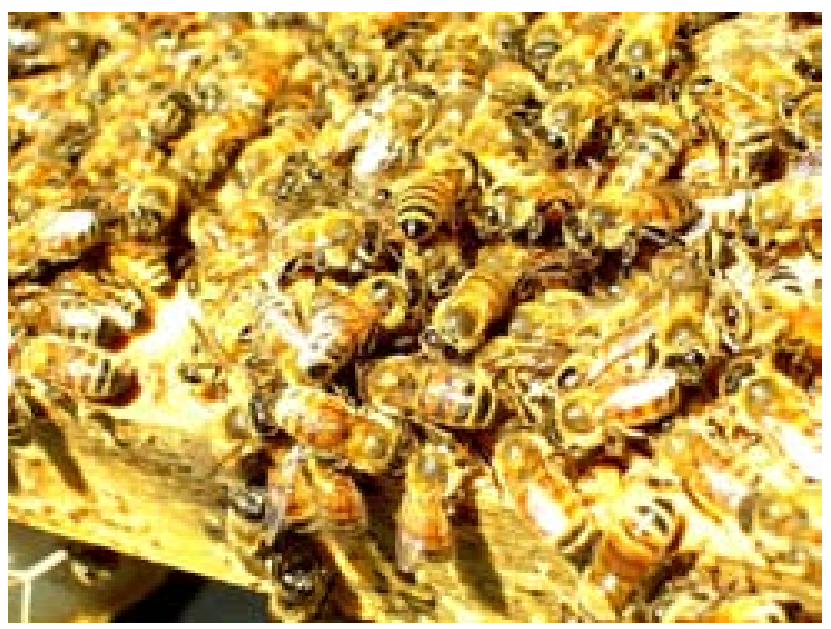

Honey bees working

Image by Marina Phillips, used under a CC BY 2.0 licence

3 Bee Improvement and Bee Breeding Association, <www.angus.co.uk/bibba/bibborig.html> Accessed 15 Feb. 2011. 


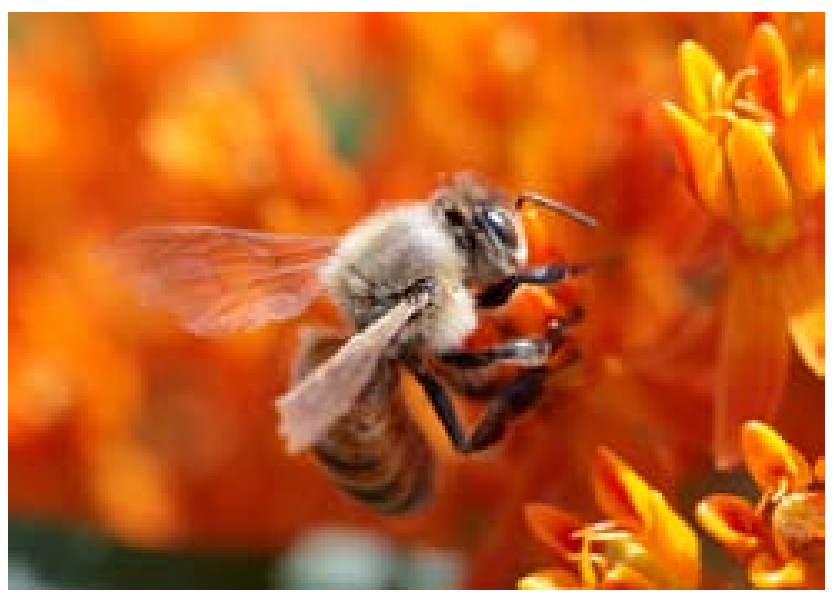

A honey bee gathering nectar

Image by Paul Stein, used under a CC BY-SA 2.0 licence

\section{Who Is She?}

But first, who is the honeybee, and what have we done to her? One way of answering the question, who is the honeybee? is via science. This is the modern way. In pre-modern cultures the question may have been answered by way of stories, stories that located the honeybee in a cosmology staked out by way of an entire matrix of stories. The scientific approach may be part of what has led to the honeybee's endangerment, but since the modern way is, for better or worse, our way, let's begin with it.

All bees belong to the order Hymenoptera ('veil winged'), which is comprised of 100,000 species, of which 25,000 are bee species, most of them of solitary habit. The social bees, such as honeybees, bumblebees and a variety of stingless bees, comprise a distinct family, the Apidae, within which honeybees make up a sub-family, Apinae, consisting of just one genus, Apis. There are four species in Apis: florae and dorata, neither of which is used in modern commercial apiculture, cerana (eastern), once cultivated extensively in China, and mellifera (western), which originated in Europe and other parts of the Old World. Apis mellifera is the main commercial species used throughout the world today, in the New World, where Apis was originally nonexistent, as much as in the Old World. Of mellifera there are twenty-four different races, each of which evolved via adaptation to the conditions of particular geographical environments. Four races of apis mellifera are used in contemporary apiculture: a.m. carnica, a.m caucasica, a.m. ligustica (Italian honeybee) and a.m. mellifera (British honeybee). Of these the Italian honeybee has become the bee of choice for the majority of commercial beekeepers (Milner). 
Like other social bees, honeybees live in colonies - in their case very large colonies, their members often numbering in the tens of thousandsmeticulously organized around the requirements of nutrition, hive construction and reproduction. Nutrition revolves around the gathering of nectar and pollen from flowering plants by foraging bees. Tiny quantities of raw nectar may be consumed in the field but mostly it is stored in the bee's honey sac then regurgitated, back at the hive, and passed from bee to bee until the water content is reduced by evaporation from $70 \%$ to $30 \%$. The fluid is then removed to open cells in the honeycomb where further evaporation is achieved by bees fanning their wings over it. When water content reaches $20 \%$ the honey is ready and the cells are capped. It takes something in the order of 10,000 flower visits for the bees to produce half a kilogram of honey (Elwood 9). Honey and pollen can also be processed, with the help of special glands in bees' heads, into royal jelly for the larvae and the queen and also into wax for the construction of the hive: at a certain point in their life cycle worker bees develop glands that convert the honey they consume into wax. The wax is extruded as small flakes through pores in the bee's abdomen; the bee chews the flakes to bring the wax to the consistency needed for construction of the hexagonal cells of the hive (Beeswax Co. LLC.). Bees also produce from plant resins a kind of bee glue with antibacterial properties; called propolis, it is used to seal cracks in the hive and embalm the corpses of any small creatures, such as mice or lizards, that accidentally fall into the hive and die, thereby potentially becoming a source of infection.

Reproduction is the responsibility of a single female, the queen, who alone lays eggs and is the progenitor of the entire colony. Most of her offspring are female and constitute the caste of workers. Though female, the workers are infertile and assume instead full responsibility for the running of the colony, where this includes caring for the larvae and defending the queen. It is they who forage for nectar and pollen and transform it into honey, wax and propolis and they who build elaborate combs for the storage of honey and pollen and the housing of larvae. ${ }^{4}$ The nest is designed for thermal regulation: it is cooled, when necessary, by water brought in by workers from outside; when heating

4 Maeterlinck describes the tasks of the workers so eloquently I can't resist quoting him again. The 'spirit of the hive' he says, 'regulates the workers' labours, with due regard to their age; it allots their task to the nurses who tend the nymphs and the larvae, the ladies of honour who wait on the queen and never allow her out of their sight; the house-bees who air, refresh, or heat the hive by fanning their wings, and hasten the evaporation of the honey that may be too highly charged with water; the architects, masons, wax-workers, and sculptors who form the chain and construct the combs; the foragers who sally forth to the flowers in search of the nectar that turns into honey, of the pollen that feeds the nymphs and the larvae, the propolis that welds and strengthens the buildings of the city, or the water and salt required by the youth of the nation. Its orders have gone to the chemists who ensure the preservation of the honey by letting a drop of formic acid fall in from the end of their sting; to the capsule-makers who seal down the cells when the treasure is ripe, to the sweepers who maintain public places and streets most irreproachably clean, to the bearers whose duty it is to remove the corpses; and to the amazons of the guard who keep watch on the threshold by night and 
is required, especially in the nurseries, workers beat their wings. (It is this capacity for thermal regulation that has enabled the honeybee to establish itself successfully in the wide range of environments and climates into which, as we shall see below, it has been introduced.)

In addition to the queen and the caste of workers there are two further castes: the first is the caste of princesses, a specialized type of larvae which have been differentially developed for an exclusive reproductive function. They are sequestered in royal apartments until the colony swarms and the old queen departs, at which point they emerge, momentarily, and compete to the death with one another to become the new queen. The second is the caste of males, a very small number of enormous, voracious, idle members of the colony known as drones, who exist only for that moment when they too will compete with one another to mate with the new queen. When that moment has passed and their purpose has been fulfilled, they will be swiftly despatched by the female workers.

In the process of foraging for nectar, honeybees incidentally gather pollen on their (specially adapted) furry legs, and since a single bee may visit thousands of flowers in the course of a day, it will serve as a highly effective vector of pollen exchange amongst flowers - in other words, of pollination. (The (female) bee is thus really a male sex organ of the flower. In this respect the honeybee exceeds our habitual categories: the idea of a mobile sex member which serves the male purpose but is not attached to the organism who produces the male gamete, and is moreover a distinct (and female!) organism in its own right, confounds our accustomed notions of sexual identity.) Many species of plant in those parts of the world in which the honeybee originated have evolved specifically for pollination by honeybees. Honeybees accordingly play an extremely important role in these ecologies. They also play an important role in human agriculture, since many of the plants pollinated by honeybees have become global food crops (Benjamin and McCallum 3-4).

Two of the most fascinating and remarked-upon attributes of honeybees are, firstly, their 'altruism', and secondly, the sophistication of their communicative capacity. The altruism is in the first instance manifested in the way the incessant daily labours of both workers and queen are directed to the good of the hive rather than to their own good as individuals. But it is also manifested in the dramatic event of the swarm, when, at the height of the prosperity of the hive, as Maeterlinck puts it with customary eloquence, when its cells are overflowing with stores and its future seems assured, the queen and more than half the

by day, question comers and goers, recognize the novices who return from their very first flight, scare away vagabonds, marauders and loiterers, expel all intruders, attack redoubtable foes in a body, and, if need be, barricade the entrance' (Chapter 2). 
population of workers renounce the city they have worked so hard to create. They face the uncertainties of homelessness, bad weather, starvation and accident as they venture forth to find a different nest site and begin the huge labour of building and populating a new city (Maeterlinck, Chapter 2). All this is undertaken in the interests of allowing a new colony, under a new queen, to set up house in the old hive.

How the decision to swarm is taken, and the time for swarming appointed, is not known. It certainly does not emanate from the queen, or from any kind of individual bee 'executives'. Maeterlinck appeals to the 'Spirit of the Hive', an intelligence that belongs to the collective and is greater than the sum of the bees' individual intelligences. The decision to swarm is not, he points out, a product of mere instinct, a blind mechanism, but is negotiated with complex sensitivity to context. If the princesses are removed from the hive, for instance, so that a new queen can no longer take the place of the departing one, the swarm will be cancelled, and everyone will settle down happily again to their old routines.

The extraordinary communicative capacities of the honeybee are well known. The activities of individual bees are clearly directed as much by information gained through communication with other bees as through instinct or mechanisms of stimulus-response. The most celebrated mode of bee communication is 'dance': worker bees returning to the hive from foraging convey to waiting workers the distance, direction and quality of nectar they have discovered on their travels, thereby recruiting more harvesters to the task. ${ }^{5}$ At the time of the swarm, too, scout bees are sent forth to locate suitable cavities for the new hive and upon their return communicate the distance, direction and dimensions of any such cavities to the eagerly awaiting colony. Such information is conveyed by either the 'round dance', for short distances, or the 'waggle dance', for longer distances; the bee runs in either a circle or a figure of eight, frequently changing directions, these changes in direction indicating both distance to the nectar and direction in relation to the sun. The intensity of waggling expresses the quality of the food. ${ }^{6}$ Bees are also constantly imparting to one another via pheromones and other forms of chemical messaging the information they need in order to coordinate the complex and context-dependent tasks required for the ongoing organization of the colony. How such tiny creatures are capable of such sophisticated cognition and communication remains one of the mysteries surrounding the whole question of the 'Spirit of the Hive'.

5 The honeybee dances were first analysed by Karl von Frisch. For a definitive account of honeybee communication, see Seeley 1995. For summaries, see Holldobler and Wilson 64-66; 169-178.

6 New honeybee dances are still being discovered. There is the 'shaking dance' to entice bees away from food processing and into foraging, and the 'tremble dance' to entice them away from foraging and back into the kitchen! See Holldobler and Wilson 74. 


\section{Why Does She Buzz?}

Contemporary biologists are loath, of course, to subscribe to Maeterlinck's rather mystical notion of the spirit of the hive, yet it is not clear that the kinds of explanations they offer dissolve the mysteries. Eminent entomologists such as Bert Holldobler and E.O. Wilson, for instance, argue that the honeybee colony can serve as a model for self-organizing systems whose apparent purposiveness is an emergent outcome of distributed intelligence. By this they mean that while individual honeybees do possess intelligence, the appearance of intelligence in the behaviour of the colony as a whole emerges statistically from aggregates of individual bee decisions and is not a holistic property of the colony itself (60). It is with considerable ambivalence, moreover, that Holldobler and Wilson are prepared to allow a kind of intelligence or mind to individual bees. They acknowledge that individual bees act autonomously, making decisions based on perceptual evidence, both immediate and remembered, and on information gained through communication with other bees. In this sense, Holldobler and Wilson concede, honeybees do 'think'. They quote Thomas D. Seeley, author of one of the most comprehensive accounts of social behaviour in honeybees to date:

It is now clear that we cannot explain the behaviour of a bee producing communication signals in terms of simple responses to immediate stimuli. Instead ... we must view her as a sophisticated decision maker, one capable of integrating numerous pieces of information (both current perceptions and stored representations) as she chooses the general type and specific form of signal that is appropriate for a particular situation. (Seeley 2003 in Holldobler and Wilson 65)

Holldobler and Wilson go on to liken bee 'thinking' to the 'thinking' of a motorist as she drives home along a familiar route. In the performance of her task she integrates cognitively but subconsciously perceptual cues from her environment with an inner road map and a reflex ability to operate the vehicle. The motorist is displaying 'perceptual consciousness' but not 'reflective consciousness'. She has a goal-to reach a predetermined destination-and she is cognitively but unreflectively making many context-specific decisions along the way in response to a variety of signals and cues. The honeybee also, according to Wilson and Holldobler, has certain goals (or, in the highly computational language of their model, 'decision rules') but unlike the goal of the motorist, hers are pre-set genetically. For the worker bee, these goals are numerous but nevertheless limited and determinate. The worker bee can, for instance, choose where to forage, but not whether to forage. ${ }^{7}$ She is free to make

7 In fact the worker bee's choices are much wider than this, as is clear from the passage from Maeterlinck quoted in endnote 4 . The point here, however, is that while she can choose amongst her ends, according to 
decisions about means but not ends. The commonality of purpose throughout the colony that this genetic predetermination of ends produces is what ensures that the decisions of individual bees give rise, at the level of the colony as a whole, to coherent, adaptive outcomes.

Hundreds of bees making such decisions more or less simultaneously yield the overall response of the superorganism. As the colony need grows, communication spreads, and more workers respond. As the need subsides, the number of engaged workers tapers off. By the law of large numbers, the workers' personal idiosyncrasies, mistakes, and lucky guesses are summed. When added to deviations either up or down through inappropriate vivacity or tepidness, they tend to cancel out and hold the colony response hour by hour close to its optimum while narrowing fluctuation around that level (Holldobler and Wilson 66).

There is, as I mentioned, considerable ambivalence in Wilson and Holldobler's account of honeybee cognition. As I have explained, they concede intelligence to individual bees, though in a form modelled on artificial intelligence and heavily inflected with the language of computer programming. To the colony as a whole they refuse mind, in the sense of a mind of its own, though they are happy, as we can see in the quote above, to characterize the colony as a 'superorganism', by which they mean a unit of natural selection in its own right. Elsewhere, however, at the start of the book, they remark that the study of superorganisms is important because of the light it might shed on how neurons in the brain interact in the creation of mind (xviii). There are, in other words, tensions in their treatment of honeybee mind, and the mystery of the 'spirit of the hive' has not, in my opinion, been entirely dispelled.

Indeed, it seems unnecessary to discount the possibility that the intense collectivity of honeybees might not give rise to a bio-electrical or other biophysical in-phaseness that constitutes the kind of permeating unity that may be the physical correlate of mind. The buzz of the honeybee is particularly suggestive in this connection: this wing-driven, high-frequency, variable vibration, which can be modified for communicative purposes but is nonetheless a background constant, may be a mechanism whereby individual bees remain collectively in-phase at all times. Or this buzz might itself be an expression of an underlying mental interconnectivity, an interconnectivity that does not override the independent mentality of the individual bee but informs it and guides it. In other words, this might be a level of mind that both emanates from, and reinforces, the bee population's collective coherence of purpose. Such mind need not have a distinct centre of its own but may manifest as a higher, holistic, guiding dimension of individual bee minds. 
In any case, it seems worth exploring the possibility that an organism can, at the same time and without contradiction, exercise its own intelligence and participate in a higher, holistic intelligence. In this, as in so many other instances, the honeybee offers an example that defies our habitual categories of identity, and with them, as we shall see, our normative assumptions.

\section{What Have We Done To Her?}

Beekeeping or apiculture, like literary interest in the mysteries of the honeybee, dates back to ancient times, but it was only in the eighteenth century, in Europe at least, that beekeepers attained a benign form of the beekeeping art, providing bees with suitable accommodation in exchange for honey that could be extracted without destroying the hive or harming the colony. Indeed, by Maeterlinck's time people had achieved a relationship with honeybees that was unusually considerate, exemplifying a kind of mutually advantageous synergy that could serve as a model for relations between the human and non-human generally. Maeterlinck himself puts it well, in a passage that could have been written by Laozi or Zhuangzi, so redolent is it of Daoist notions of acting with rather than against the grain of nature. Speaking of the successive improvements to the design of the artificial hive and successive techniques of management, he says, 'Man truly became the master of the bees, although furtively, and without their knowledge; directing all things without giving an order, receiving obedience but not recognition ... he does with them what he will, he obtains what he will, provided always that what he seeks be in accordance with their laws and their virtues...' (Chapter 1). In other words, by generously providing conditions in which bees could happily enact their law and fulfil their own destiny, beekeepers in Maeterlinck's time maximized their own rewards.

How things have changed in apiculture since then! Today the honeybee is exploited not principally for honey but for pollination services. Wherever honeybee-pollinated crops of the Old World are grown on the planet today, honeybees have been introduced to pollinate them. These crops are often grown in vast monocultures, like the almond orchards in California, which supply $80 \%$ of the world's almonds. Such crops flower - in spectacular monochrome - for only a couple of weeks of the year, leaving the rest of the year flower-free and hence uninhabitable by honeybees. Since this is a zone which cannot support wild honeybees, and since naturally occurring populations of honeybees could not in any case begin to cope with the volume of blossom that comes on line when the almond orchards flower, over a million commercial hives have to be trucked in at the time of flowering, and specially bred bees set to work gathering nectar and thereby pollinating the crop. Apiarists can earn more than $\$ 100,000$ in the almond season, which lasts little more than three weeks (Benjamin and 
McCallum 6). When flowering finishes, the hives are trucked out again, and on to the next job, another vast pink or white monoculture ... and so on throughout the year.

Under these commercial conditions there is no respect for seasonality, for the customary winter dormancy of the hive, for life cycles and swarms, for variety of colour and perfume and nectar flow nor hence for well-balanced bee nutrition. There is no respect either for the indigeneity of the race of honeybee appointed for the job, for adaptation to climate or terrain, for genetic diversity: bees are selected for commercial qualities, and one or two races of honeybee have become the commercial standard, out-competing and eclipsing native bees wherever they have been introduced. Breeders breed billions of these standardized bees from a small number of specially bred queens, thus reducing genetic diversity further. In short, bees are treated as cogs in an agricultural machine, and pollination is converted into an industry (Benjamin and McCallum, Chapter 3, Chapter 9). Such industrial apiculture could hardly provide a starker contrast to the apiculture described by Maeterlinck, with its loving attention to the needs, aspirations and house-proud aesthetic sensibilities of the revered little bee.

And what is the result of the industrialization of apiculture? A weird new condition, called colony collapse disorder, that is leaving hives in many parts of the world eerily empty, Marie Celeste-like, their foragers vanished, the young nurse bees who care for the newborns absconded, eggs, larvae and queens abandoned. The vacant hives themselves are avoided by other insects who would normally move in and occupy them; even honey left in the combs is untouched by neighbouring bees, who again under normal circumstances would be quick to help themselves to it. As noted above, in the last two years a third of all honeybees have mysteriously disappeared in the United States, while large numbers of hives have also collapsed in Canada, Europe, Asia and South America (but not in Australia). No-one has yet conclusively identified a cause of the disorder, though chronic stress occasioned by malnutrition from monocultures, lowered resistance from shrinking gene pools, maladaptation to multiple environments and the disruption entailed by constant trucking surely underlies whatever the 'cause', in the sense of trigger, may turn out to be. (This explanation is borne out, if borne out it needs to be, by the fact that non-commercial bees belonging to amateur small-scale apiarists in American cities are not suffering colony collapse disorder (Harmon).) Of this 'cause', some have suggested that it might be the varroa destructor mite, long-time parasite of honeybees, though there are colonies infested with the mite which are not suffering collapse. (Australia is the only continent that is at present varroafree.) Other possibilities are the pesticide used to eradicate the mite or the new nicotine-based pesticides, called neonicotinoids, that are used on crops serviced by honeybees. Neonicotinoids are applied to soil and taken up into plant tissues, 
including pollen and nectar. Effects of neonicotinoids on target insects, such as termites, include immune system failure and disorientation, which accords well with the symptomology of colony collapse disorder. It is hardly surprising that if substances lethal to insects are applied to, and absorbed by, plants, the effects of those substances may later turn out to be lethal to the bees who drink from the plants. Other threats with which the currently immunologically compromised honeybee has to contend include a tracheal mite that attacks the respiratory system, a fungus that affects the digestive tract and an acute paralysis virus.

This then is the pass to which we have brought the valiant honeybee. Whatever the exact trigger for colony collapse disorder, it is obvious that the bee is succumbing to the combined effects of the profoundly un-Daoist industrialization of apiculture, with its total disregard for the 'law and virtue' of her nature.

\section{Does What We Have Done To Her Matter?}

Does the loss of the honeybee - if lose her we do - matter? What do we lose in losing her?

The first, self-interested or instrumentalist answer to this question is that if we lose the honeybee we also lose approximately one third of the world's crops. Crops currently commercially pollinated by honeybees include, amongst more than a hundred others, almonds, peaches, soybeans, apples, pears, cherries, various berries, melons, cucumbers, nuts, onions, carrots, broccoli, sunflowers, oranges, avocados, alfalfa (which is fed to cattle and is thus used in the production of both beef and dairy) and cotton (Benjamin and McCallum 3-4). Most of these crops can be pollinated by other insects, including other species of bee, but far less effectively and less readily, especially since many of these insects have already been displaced in the wild by the commercial honeybee and her feral relatives. ${ }^{8}$ Crops can also be pollinated, with vast labour-intensiveness, by hand. Resort to such alternative methods however would have extremely adverse short- and medium-term economic consequences.

It is not of course only crops that would suffer from the demise of the honeybee. The honeybee is a key pollinator of flowering plants in nature at large, and hence in an ecological sense a keystone species. A major failure of pollination would result in the demise of many wild-growing herbaceous, shrub and tree species

8 According to a recent article in Scientific American, the solitary blue orchard bee (also known as the orchard mason bee) is currently being groomed to join the honeybee as a commercial pollinator. These bees live in boreholes in trees and do not produce honey. As pollinators of tree fruit crops they are extremely efficient, one blue orchard bee doing the work of more than fifty honeybees. However, blue orchard bees, being solitary rather than social, cannot be bred in the numbers needed for commercial pollination on a grand scale (Mims). 
and hence too the many birds and other vertebrate species that depend on them. The destabilizing effects of such collapse for the biosphere as a whole, while not specifiable in advance, would clearly be extreme, and would inevitably entrain further economic consequences. Speaking of the 'valuable services' rendered by insects in general, and homing in on just a couple of these - the role of flying insects as the primary food source for freshwater fisheries, for instance, and the role of dung beetles in cleaning up cattle manure in the rangelands, thereby increasing the available forage for cattle - one entomologist tried to put a dollar figure on such services. He concluded, with under-statement almost touching in its naivety, '[o]ur biological infrastructure is vulnerable to degradation. If we do not take care of it, it will break down and could seriously impact the economy' (Biello).

Most of the current discussion of colony collapse disorder in the press and the popular media, including the popular science media, remains focussed on its commercial and economic impacts, though few commentators seem really to grasp the potential enormity of these impacts. If a third of the world's crops were indeed suddenly, within the next few years, to disappear, this would have to punch holes in the global economy that would surely cause it simply to founder and sink. (What economist would ever have imagined that the longforetold collapse of world capitalism would be triggered by a honeybee? Such a possibility was beyond the parameters of economics.)

But the unselfconscious economism and instrumentalism that characterizes the popular treatment of colony collapse disorder entirely fails to capture the deeper import of this phenomenon. It fails to account for the grief that many of us feel on hearing of this quiet abdication of the honeybee in face of pressures even its indomitable spirit cannot withstand. And, to return to the questions posed at the beginning of this paper, it does not begin to shed light on the fact that the fate of the honeybee seems to call forth from us a slightly different register of despair from that called forth by the more familiar icons of extinction-polar bears and orang-utans and such like. How to account for this despair? Is it a moral reaction, desolation at yet another instance of the moral failure of modern industrial civilization in its attitude to nature? Yes, it is that. The disappearance of the honeybee is indeed another instance of this vast moral failure and there is unquestionably an element of moral outrage in our reaction. It's been a shock for many people even to learn that a 'pollination industry', with its attendant factory-farming of bees, exists, and that pollination is no longer, at least in agriculture, a wild process. It is even more shocking to hear beekeepers in the United States admitting that bees have become over-worked and undernourished and unquestionably stressed (Benjamin and McCallum, Chapter 9). Perhaps, as I shall suggest, the shock we feel at the very idea of 'over-worked 
bees' and the desolation that overwhelms us as we contemplate the honeybee's abdication from our world cannot ultimately be explained entirely in terms of ethics, but ethics is undoubtedly an element of it.

Let us pause for a moment to reflect on this - on how the significance of the honeybee's demise might be configured from the perspective of environmental ethics. Environmental ethics has rested on questions of moral considerabilitywhat it is that makes living things, aside from humans, matter, morally speaking. In answering this question, environmental ethicists have cited a range of attributes, from consciousness or intelligence or sentience at one end to the bare telos (self-purpose), agency, intentionality or conativity (will to self-existence) of living systems at the other. In other words, what makes things matter, from this point of view, is something to do with mind: things endowed with mentality of some kind or in some degree, even if it is just the bare conativity of plants, have ends or interests that distinguish them, in a morally categorical way, from inanimate objects. They matter to themselves, so we cannot-ought not - treat them in the same way we treat objects which do not matter to themselves.

How do honeybees fare against such a criterion of mattering? The individual honeybee has a life and interests of her own - she is, in the phrase of environmental philosopher, Paul Taylor, a 'teleological centre of life'. She exhibits conativity, and, as a decision-maker, agency. She is sentient; she even, according to the most respected entomologists in the field, 'thinks'. Measured against the usual criteria of moral considerability in environmental ethics, then, the honeybee makes the grade. But she is so little! It is hard to regard her as on a par, morally speaking, with an elephant or a dog or even a mouse. Admittedly, if we rank her lower than such animals, on account of their satisfying the criteria for mattering to a greater degree than she does, this will introduce a species hierarchism into our moral thinking, a form of moral hierarchism that may ultimately return us to the kind of anthropocentrism from which environmental ethics sought to deliver us. For, measured against any ladder of moral value defined in terms of the kind of inner, self-directed striving that ultimately emanates in some form of mentality, we humans are likely to come out on top. This will reinstate, at least to some degree, a privileging of human interests over the interests of most other species, a privileging that is consistent with anthropocentrism. But if we refuse to hierarchize, and insist that properties such as telos, agency, conativity, do not admit of degree, and that all organisms are consequently morally equal, we are saddled with a strict 'biocentric egalitarianism' that requires us to treat the life of a honeybee as on a par, morally speaking, with that of a wolf or a whale. ${ }^{9}$ This position strains credulity, and, if taken seriously, would likely lead to morally dubious consequences.

9 'Biocentric egalitarianism' is a term with currency in the work of Norwegian ecophilosopher Arne Naess, and other deep ecologists. 
So - without trying to resolve this tough issue in environmental ethics - we can see that the grief we feel at the disappearance of the honeybee might be partly indeed a moral reaction to the loss of individual bees, but that this might not fully account for the depth of our grief. In other words, what matters about the disappearance of the honeybees might be something more than the loss of the bees as individuals. Might it also then be the loss of honeybee colonies; that is, might it be the colony rather than the individual that is, in this connection, the main locus of moral considerability? In destroying a hive might we be destroying something approximate to a larger, holistic organism? Perhaps. If we concede, as I suggested earlier, that the colony as a whole might possess an immanent mentality, distributed across the minds of individual bees but transformative of their thinking, and in that sense more than the sum of their otherwise independent mentalities, then the colony might count as morally considerable in its own right, its considerability comparable in degree to that of a wolf or a whale.

Maybe so. However, this manoeuvre does not seem quite to catch the source of our grief either. It is not at the destruction of hives per se that we are desolated. It is more at the prospective loss of honeybees as a species. It is for the possible extinction of the honeybee that we grieve.

Is this still an instance of moral mattering? Are species objects of moral considerability, so that it makes sense morally to regret the loss of a species over and above the loss of the individuals or populations that make it up? In other words, in the case of honeybees, is it the species itself which is of exceptional moral significance even though the moral significance of the individuals - bees or colonies - who make it up is only modest?

Yes. But we should note that the whole question of the moral standing of species is philosophically problematic because a species is not in itself a tangible thing. It is not an entity with a life and interests of its own. It cannot act and it cannot strive. A species is a universal, partly actualised via instances but partly forever merely potential, a kind of abstract Form that hovers behind, and is never exhausted by, its actual instances. As a Form, it does not seem an appropriate object of moral concern. It does not seem to fit the concrete categories - of person, being, entity - for which ethics was made. It seems more to belong to the province of aesthetics: a species is valued for the unique contribution it makes to the beauty or variety of the world.

This is a conundrum that makes the extinction of species an elusive issue in environmental ethics, despite being at the same time at the heart of the discourse. But there is a way of dealing with this conundrum. If we take the ecosystem itself - or ultimately the biosphere as a whole - as a locus, perhaps the principal locus, of moral concern, then species can derive moral value from the 
contribution they make to the integrity, stability and viability of the ecosystem, as Aldo Leopold argued in the articulation of his land ethic. A species with a key ecological role in a given ecosystem will have a high moral value, relative to the ecosystem in question, even if its individual members are of minor intrinsic moral significance as 'teleological centres of life' ${ }^{10}$ This does seem to correspond with our intuitions concerning the moral status of the honeybee. Fond as we may be, on the one hand, of the bee herself as a lively bundle of purposes and responsibilities which it behoves us to respect, most of us are not likely to weight her life equally with that of a wolf or a whale; yet, on the other hand, we may grieve for her loss as a species as much, or more, as we grieve for the loss of a species of wolf or whale. And this is surely because the honeybee is indeed a keystone species for the biosphere.

In contemplating the bleak reality of colony collapse disorder, then, we are faced with the prospect of ecological breakdown. Humanity has, we know, for decades been recklessly ripping and slashing, gouging and pulverizing, poisoning and expropriating the living tissue of earth, but now it seems that under this assault the very structure of the biosphere, the intricate ecological jigsaw of the life-system, is finally starting to come apart. Without honeybees, the renewal of plant life is impaired, and with impairment of plant renewal, terrestrial life generally is doomed.

In grieving at the disappearance of the honeybee, then, I am grieving for the diminishment of the biosphere. This diminishment, of anthropic origin, surely represents a moral wrong, but there is nevertheless still more to this grief of mine than moral anguish. I am desolated because the diminishment of the biosphere is not merely a loss to it but also a loss to me, an intimate loss that somehow implicates the whole of myself. What kind of loss is this?

With the unravelling of the biosphere, I would suggest, comes the unravelling of the story to which, unwittingly, we all belong, the story that has underpinned all cultures, all belief systems in human history and evolution. This story is the story of the earth. It is a tale of symphonic synergies in which the elements of nature intimately shape one another and collectively achieve the great metabolic processes of earth: photosynthesis, pollination, seed dispersal, soil production and soil fertilization, thermal and atmospheric regulation, the endless recycling of water, carbon, nitrogen through the system ... processes that assure the inexhaustible regeneration of life. This is the proto-story that sets the stage for the smaller stories we tell ourselves - the religions, myths, histories, ideologies, all the narratives by which we give meaning to our lives. The intricate jigsaw

10 This is the line taken in a recent paper by Charles Cockrell tackling a comparable issue: how to assign adequate moral significance to microorganisms, given their evident lack of moral congruence, as individuals, with larger organisms. 
of the biosphere-where everything fits with everything else, where everything conspires with everything else continuously to bring forth new form and life, where even death itself is continuously converted back into life - this is the very template of story, of events coming together meaningfully into coherence and intelligible form and unfolding towards intended and normative ends. Since this larger story, the story of earth, is the proto-story for all the cultural narratives by which we impose meaning on our lives, this larger story, the story of earth, is the template for meaning itself. ${ }^{11}$

Honeybees, as it happens, are not merely physically key to the constitution of the biosphere and hence to the preservation of this proto-story. The beehive itself is also, figuratively, a microcosm of the biosphere, a concise and comforting poetic image for the architectonics of ecology. Built out of the living substance of bee bodies, the combs of the hive evoke, in their intricate cell-structure, the architecture of niches that characterizes the biosphere. Each niche in the biosphere is inhabited by a specialized kind of entity which, like the different castes of bees in a hive, works toward the fertility and nourishment of the whole. These different kinds of entity are communicative and sentient in their own right yet also unwittingly contribute to, and participate in, a larger, immanent agency and intelligence, that of the hive as a whole, which informs, and gives urgency and purpose to, the activities of its inhabitants. The beehive models the normativity of a system in which each individual pursues its own ends yet in doing so satisfies exactly the needs of others in the system. The endresult of this inter-coherence of ends is poetically delivered, in the lexicon of the beehive, as honey, the sweet gift, or taste, of aware-self-existence that each bestows on others when all follow desires that spring from within them but are at the same time inflected by the wisdom of the greater whole, the hive.

It is this inter-coherence of desires, so strikingly exemplified in the image of the beehive, that is the normative key to living systems generally, indeed to the biosphere. Only via such inter-coherence can aware-self-existence-the ultimate end of all our strivings - be generated. And such inter-coherence, according to which the desires of each individual also happen, incidentally, to secure the conditions necessary for the existence of others, is at the same time self-evidently a proto-ethics: a code of mutuality. The proto-typal story, then - the story of earth - is already proto-ethical, which is why stories, in their

11 For a fascinating account of the idea that narrative generally is the ground of cultural meaning, with concepts originating not as bare namings of pre-given objects, as common sense supposes, but rather via the ceremonial incorporation of objects into stories, see Craig San Roque, 'On Tjukurrpa: Painting Up, and Building Thought'. It is only when the world is storied, according to this view, that a conceptual frame of meaning is created through which human life can be thought about. It is thus necessary for cultures to create repertoires of Dreaming stories - myths - that serve as primordial templates for concepts and hence for thought/intelligibility. San Roque details the process whereby the raw human experience of world, still entangled with the particularity of geography and topography, becomes transmuted, via ceremony, into story and thence into concept. 
archetypal manifestations in our cultures, are never without a moral. We are meant to learn from them. Stories are meant to teach us the basic dynamics of life so that we can correct ourselves when we go wrong. Yet story, in this original, normative sense, out of which our foundational myths and religions constellate, refers back necessarily to the normative template of the biosphere. If this template starts to unravel, it will follow that everything is in jeopardy. Not merely our own physical existence and the physical existence of all species, together with the ethical import that attaches to this, but the proto-story which is the very ground of meaning, relative to which alone anything can possibly matter.

Without our ever acknowledging it or even being aware of it, then, the story of earth has provided the ongoing meaning-context for human life. It is the primal meaning into which we are born and to which we belong. In the presence of this story we have always had the opportunity to step back from the chaos and uncertainty of personal and public affairs and find reassurance in the dawn chorus or the first buds of spring or the summer radiance of sunlight through leaves. Without this structure of story supporting us, we would be utterly adrift, with no idea of what we were doing in the universe or of what the point of our existence was. Indeed, so taken for granted has this story been in the past, so backgrounded in our consciousness, it did not occur to us that it could be lost. But now this has occurred to us. To our almost inexpressible dismay, holes are appearing in the story, and meaning is beginning to leak out. The bees are leaving. The sun is dimming. The ice is melting. Spring is early or late. Without bees, seeds become scant and weeds no longer spring up in the vacant lot. The ground remains bare. In so many human households the television is still blaring, still pumping out its incessant dramas, but the greater story which gives direction to all narrative is leaking. Soon there will be a thousand holes in it and meaning will not merely be leaking but gushing out.

This then, I think, is the desolating portent we intuit when we confront the disappearance of the honeybee. The beehive is the story of the biosphere told in miniature. The story of the biosphere is the proto-story, the condition for all stories, all meaning. The disappearance of honeybees is a portent not merely of ethical catastrophe nor merely of physical demise but of something more ultimate: the unravelling of the larger context of meaning itself, the context in which ethics and even extinction can matter.

Freya Mathews is Associate Professor of Philosophy at La Trobe University, Australia. She is the author of several books and articles on eco-philosophy, including Reinhabiting Reality: Towards a Recovery of Culture (2005) and For Love of Matter (2003). 


\section{Works Cited}

Beeswax Co. LLC. 'How Bees Make Wax.' <http://www.beeswaxco.com/ howBeesMakeWax.htm> Accessed 15 Feb. 2011.

Benjamin, Alison and Brian McCallum. A World Without Bees. London: Guardianbooks, 2008.

Biello, David. 'Insects Provide Billions in Free Services.' Scientific American, 3 April 2006. <www.scientificamerican.com/article.cfm?id=insects-providebillions $>$ Accessed 15 Feb. 2011.

Cockrell, Charles. 'The Value of Microorganisms.' Environmental Ethics 27.4 (2005): 375-390.

Ellwood, Wayne. 'Why are they dying?' New Internationalist 425, September 2009, 4-7.

Frisch, Karl von. The Dance Language and Orientation of Bees. Cambridge MA: Belknap Press of Harvard University Press, 1967.

Harmon, Katherine. 'Urban Beekeepers Keep Cities Abuzz with Pollinators.' Scientific American, 31 March 2009. <www.scientificamerican.com/article. cfm?id=urban-beekeeping-pollinators $>$ Accessed 15 Feb. 2011.

Holldobler, Bert and E.O. Wilson. The Superorganism: The Beauty, Elegance and Strangeness of Insect Societies. New York: W.W. Norton, 2009.

Leopold, Aldo. 'The Land Ethic.' A Sand County Almanac. Oxford: Oxford UP, 1949.

Maeterlinck, Maurice. The Life of the Bee. Trans. Alfred Sutro. New York: Dodd, Mead and Co, 1928. <http://www.eldritchpress.org/mm/b.html> Accessed 15 Feb. 2011.

Milner, Ashleigh. 'An introduction to understanding honeybees, their origins, evolution and diversity.' Bee Improvement and Bee Breeding Association. <http://www.bibba.com/origins_milner.php> Accessed 15 Feb. 2011.

Mims, Christopher. 'Plan Bee: as Honeybees Die Out, will other Species take their Place?' Scientific American, 31 March 2009. <http://www.scientificamerican. com/article.cfm?id=other-bee-species-subbing-for-honeybees $>$ Accessed 15 Feb. 2011.

San Roque, Craig. 'On Tjukurrpa: Painting Up, and Building Thought.' Social Analysis 50.2 (2006): 148-172. 
Australian Humanities Review - Issue 50

Seeley, T.D. The Wisdom of the Hive: The Social Physiology of Honey Bee Colonies. Cambridge MA: Harvard UP, 1995.

Seeley, T.D. 'What studies of communication have revealed about the minds of worker honey bees.' Genes, Behaviour and Evolution of Social Insects. Ed. T. Kikuchi, N. Azuma and S. Higashi. Sapporo, Japan: Hokkaido UP, 2003. 21-33.

Taylor, Paul. Respect for Nature. Princeton: Princeton UP, 1986.

Wilson, E.O. The Creation. New York: W.W. Norton, 2006. 